\title{
Análise da viabilidade técnica da instalação de células fotovoltaicas na Faculdade de Ciências Aplicadas da Unicamp
}

\author{
Ingrid F. Evangelista*, Mirella M. Boa Morte, leda Kanashiro Makiya.
}

\begin{abstract}
Resumo
Este projeto analisa a viabilidade técnica da instalação de painéis fotovoltaicos no estacionamento do Campus da Faculdade de Ciências Aplicadas da Unicamp, apresentando dupla funcionalidade, de sombreamento dos automóveis e geração de energia. Foram levantados dados sobre o consumo de energia do campus, considerando ponderações referentes aos períodos de consumo e o comportamento da demanda energética do campus. Apos esta verificação deu se análise dos equipamentos e materiais para execução da avaliação técnica na colocação dos painéis no estacionamento. Este é um estudo exploratório, baseado na revisão da literatura sobre conceitos básicos de Smart City, Smart Grid, Microgrid, células fotovoltaica e do sistema bidirecional.
\end{abstract}

Palavras-chave: Smart Grid, Microgrid, Células Fotovoltaicas.

\section{Introdução}

Devido ao crescimento acelerado da população mundial, mais precisamente da população urbana, houve um aumento da discussão sobre as questões que norteiam o aumento populacional estas que causam implicações em aspectos como a saúde, a migração, a urbanização e a escassez de recursos que geram uma demanda maior por habitação, alimentos, energia, entre outras questões (ONUBR, 2017).

De acordo com a Agência Nacional de Energia Elétrica (ANEEL) que em abril de 2017, o país possuía uma matriz oriunda de sete fontes de energia com suas respectivas contribuições, para geração total, de: biomassas $(8,7 \%)$; eólica $(6,5 \%)$; fóssil $(16,9 \%)$; hídrica $(61,6)$; nuclear $(1,2$ $\%)$; solar $(0,01 \%)$; e importação $(5,1 \%)$.

Visto o atual panorama brasileiro o objetivo deste trabalho é desenvolver um estudo sobre a viabilidade técnica do uso de células fotovoltaicas na Faculdade de ciências aplicadas da Universidade Estadual de Campinas com o intuito de ressaltar a relevância do tema referente ao uso de energias sustentáveis e o uso da energia e impacto desta no ambiente proposto. Com o intuito de analisar o conceito de smart grid e a dinâmica das microgrids através do uso das células fotovoltaicas

\section{Resultados e Discussão}

Com os resultados levantados referentes ao estudo de caso temos que a energia consumida sofre constantes variações que são regidas de acordo com o período letivo este que vai de fevereiro a dezembro gerando maiores gastos de energia para o campus.

Sobre os modelos de placas e inversores, estes possuem vários modelos com eficiência semelhante, logo o modelo aqui escolhido visa uma maior produção de energia solar aliada a um custo-benefício satisfatório.

A respeito da energia obtida pela aplicação deste sistema microgrid, apresentado tabela 1, temos um número aproximado de placas por fileira do estacionamento, do suprimento da demanda e da distribuição à comunidade em situação de vulnerabilidade ao redor do campus, temos que este atende às necessidades do principal beneficiário da implantação do mesmo, com apenas a aplicação em 3 fileiras do sistema.

Tabela 1. Geração de energia.

\begin{tabular}{|c|c|c|c|c|}
\hline $\begin{array}{l}\text { Horas de } \\
\text { incidência } \\
\text { solar }\end{array}$ & $\begin{array}{l}\text { Total } \\
\text { KW/D } \\
\text { (dias) }\end{array}$ & $\begin{array}{c}\text { Total de } \\
\text { KW/M } \\
\text { (mensal) }\end{array}$ & $\begin{array}{l}\text { Total de } \\
\text { KW/M- } \\
\text { Efetivo }\end{array}$ & $\begin{array}{c}\text { Total de KW/M } \\
\text { Fornecidos à } \\
\text { comunidade }\end{array}$ \\
\hline 2 & 85,8 & 2574 & 2471,04 & 1921,04 \\
\hline 4 & 171,6 & 5148 & 4942,08 & 4392,08 \\
\hline 6 & 257,4 & 7722 & 7413,12 & 6863,12 \\
\hline
\end{tabular}

Fonte:Elab̄orado pelo autor, 2018

\section{Conclusão}

A geração de energia é um tema recorrente e necessário para a gestão dos problemas referentes as questões energéticas e o uso do sistema de microgrid surge como uma nova iniciativa para suprir essas questões.

As células fotovoltaicas representam uma alternativa sustentável não apenas do ponto de vista ambiental e técnico devido a sua efetividade na geração de energia. O projeto inicial visa a colocação de placas em apenas três fileiras do estacionamento, assim suprindo o efetivo e o restante sendo conduzido para comunidade e com isso gerando efetividade para futuras expansões do projeto para o restante da extensão do estacionamento, corroborando assim para a viabilidade desta microgrid.

\section{Agradecimentos}

Gostaria de agradecer à Mirella pela parceria de trabalho e amizade na elaboração deste trabalho e a professora leda por todo apoio, carinho e orientação.

$\mathrm{E}$ ao CNPq por fornecer o fomento a este trabalho.

\footnotetext{
AGÊNCIA NACIONAL DE ENERGIA ELÉTRICA (ANEEL).Matriz de Energia Elétrica. Disponível

em:http://www2.aneel.gov.br/aplicacoes/capacidadebrasil/OperacaoCapacidade Brasil.cfm. Acesso em: 22 de Abril de 2017.

ORGANIZAÇÃO DAS NAÇÕES UNIDAS NO BRASIL (ONUBR). A ONU e a População Mundial. Disponível

em:https://nacoesunidas.org/acao/populacao-mundial/ . Acesso em: 19 de Abril
} de 2017 